\title{
Drug Regulatory Affairs in Quality Management
}

\section{Suryakanta Swain* and Sangeet Sarita Mishra}

Department of Pharmaceutics, Roland Institute of Pharmaceutical Sciences, Berhampur-760 010, Odisha, India

\section{Structure of the Editorial}

Drug regulatory bodies in the recent era have emerged as an important governing body for maintaining safety and efficacy of social health. It plays the major role starting from initial establishment of a pharmaceutical industry to safe guard the marketed drug. It controls the overall quality system chain of a pharmaceutical product, which is to be purchased and utilized by the public in need.

DRA abides strict guidelines for various pharmaceutical bodies ensuring the compliance with regulations for proper quality management of a marketed drug. It's a mammoth task for pharma sector to ensure quality with output and profit along with cGMP compliances. Recently, the news flashed of penance to generic icon Ranbaxy Ltd., accused of misreporting and breaching cGMP guidelines leading to shut down of its sales and foreign trade. This shows the weightage of DRA in global pharma sector.

Introduction of newly evolved pharmacovigilance (PV) multi nationally, has brought a radical change in adverse drug reaction (ADR) monitoring. Propagation of PV activities has enabled the clinicians provide the effective decisions in ADR monitoring and rational drug use. DRA stretches its hand even to Research \& Development sector of pharmaceutical industries that has enabled the research personnel look at benefit-risk ratios of a drug molecule and finally launching the molecule for empowering human health pedigree.

Center for drug and evaluation research (CDER) a USFDA regulatory body comprising of experienced health care professionals, who piece together the overall activity of NDA and ANDA filling for new drug and generics which in turn allows the best drug in the international market. Thus, DRA acts as a powerhouse to global pharma sector, pumping enthusiasm and guidance to produce quality products. Moreover, DRA with some of its liberal approach to a new drug discovery, not only benefits mankind but also encourages the innovative ideas to make this world a better place to live in.

On behalf of the editorial board of Pharmaceutical regulatory affairs-Open access Journal, I would like to thank the OMICS publishing Group 5716 Corsa Ave., Suite 110 Westlake, Los Angeles, CA 91362-7354, USA for giving me another opportunity to write an editorial article.
*Corresponding author: Suryakanta Swain, Roland Institute of Pharmaceutical Sciences, Department of Pharmaceutics, Berhampur-760 010, Odisha, India, Tel: +91-9438038643, Fax: +91-680-2404112; E-mail: swain_suryakant@yahoo.co.in

Received May 03, 2014; Accepted May 05, 2014; Published June 02, 2014

Citation: Swain S, Mishra SS (2014) Drug Regulatory Affairs in Quality Management. Pharmaceut Reg Affairs 3: e132. doi:10.4172/2167-7689.1000e132

Copyright: @ 2014 Swain S, et al. This is an open-access article distributed under the terms of the Creative Commons Attribution License, which permits unrestricted use, distribution, and reproduction in any medium, provided the original author and source are credited. 